\title{
Etnicidad y censos: los conceptos básicos y sus aplicaciones
}

Ethnicité et recensements: concepts de base et applications

Ethnicity and censuses: Basic concepts and applications

José A. Lloréns

\section{(2) OpenEdition}

Journals

Edición electrónica

URL: http://journals.openedition.org/bifea/6802

DOI: $10.4000 /$ bifea.6802

ISSN: 2076-5827

Editor

Institut Français d'Études Andines

Edición impresa

Fecha de publicación: 1 diciembre 2002

Paginación: 655-680

ISSN: 0303-7495

Referencia electrónica

José A. Lloréns, «Etnicidad y censos: los conceptos básicos y sus aplicaciones », Bulletin de l'Institut français d'études andines [En línea], 31 (3) | 2002, Publicado el 08 diciembre 2002, consultado el 10 diciembre 2020. URL : http://journals.openedition.org/bifea/6802 ; DOI : https://doi.org/10.4000/bifea 6802

\section{(c) $(1)$}

Les contenus du Bulletin de l'Institut français d'études andines sont mis à disposition selon les termes de la licence Creative Commons Attribution - Pas d'Utilisation Commerciale - Pas de Modification 4.0 International. 


\title{
ETNICIDAD Y CENSOS: LOS CONCEPTOS BÁSICOS Y SUS APLICACIONES
}

\author{
José A. LLORÉNS
}

\begin{abstract}
Resumen
En este artículo se revisa el concepto de etnicidad y la manera en que se operacionaliza en los censos nacionales de población. El reconocimiento de la necesidad de registrar las características de etnicidad en los países latinoamericanos es en general un proceso relativamente nuevo, derivado a su vez de la variedad de dinámicas socioculturales que presenta cada país de la región y de los motivos particulares que promueven en cada país esta necesidad de registro. De ahí que la conceptualización de la etnicidad difícilmente puede ser aplicada por igual a cada una de las realidades nacionales, lo que se refleja en la operacionalización de cada conceptualización en el ejercicio censal. Todo esto complica los esfuerzos por establecer de criterios y procedimientos estadísticos normalizados que habiliten la aplicación de instrumentos técnicamente aceptables y a la vez políticamente admisibles sobre cuya base se pueda comparar la situación de dichos grupos en los distintos países de la región. A pesar de todo, creemos que es necesario seguir tratando de avanzar en esta dirección. Una estrategia considerada puede permitir un avance conceptual relativamente más seguro. Se trata de empezar por revisar las nociones más recientes sobre etnicidad teniendo como referente concreto una realidad nacional específica pero que contenga elementos similares a la situación de otros países en la región. Es el caso del Perú, donde se encuentran presentes, aunque en proporciones muy variadas, poblaciones originarias y afrodescendientes. En este artículo, y teniendo como referente a esta nación andina, se hace primero una sucinta consideración de las principales perspectivas actuales sobre etnicidad, para luego discutirse algunas de las implicancias de su operacionalización en los ejercicios censales de población.
\end{abstract}

Palabras claves: Etnicidad, censos de población, primordialismo, constructivismo, contextualismo, América Latina.

\section{ETHNICITÉ ET RECENSEMENTS: CONCEPTS DE BASE ET APPLICATIONS}

\section{Résumé}

Cet article examine le concept d'ethnicité et la façon dont les recensements nationaux l'opérationnalisent. La reconnaissance du besoin d'identifier les caractéristiques ethniques des

* INEI, General Garzón 658, Jesus María Lima 11, Perú. E-mail: jllorens@ @inei.gob.pe 
les pays d'Amérique latine est, en général, un processus relativement récent, qui provient de la variété de dynamiques socioculturelles que présente chaque pays de la région et des raisons particulières qui motivent ce besoin d'identification dans chacun des pays. La conceptualisation de l'ethnicité peut donc difficilement être appliquée de la même manière à chaque réalité nationale, ce qui est reflété dans l'opérationnalisation de chaque conceptualisation lors des recensements. Tout ceci complique les efforts en vue d'établir des critères et procédures statistiques normalisés qui rendent possible l'application d'instruments techniquement acceptables et, à la fois, politique $\neq$ ment admissibles pouvant servir de base à la comparaison de la situation de ces groupes dans les différents pays de la région. Malgré tout, il est, selon nous, nécessaire de persévérer dans cette direction. Nous considérons qu'une stratégie qui permet un progrès conceptuel relativement plus sûr consiste à commencer par l'étude des notions les plus récentes sur l'ethnicité, en ayant comme référence concrète la réalité nationale spécifique d'un pays qui, cependant, contiendrait des éléments semblables a la situation d'autres pays de la région. C'est le cas du Pérou, où l'on retrouve, bien que dans des proportions très variées, des populations d'origines autochtone et africaine. En prenant ce pays andin comme référence, cet article présente d'abord un résumé succinct des principales perspectives actuelles concernant l'ethnicité, puis discute quelques unes des implications de son opération $\neq$ na $\neq$ lisation lors des recensements de population.

Mots-clés : Ethnicité, recensements, primordialisme, constructivisme, contextualisme, Amérique latine.

\title{
ETHNICITY AND CENSUSES: BASIC CONCEPTS AND APPLICATIONS
}

\begin{abstract}
In this paper, the concept of ethnicity and the manner in which it is operationalized in national censuses are reviewed. Recognizing the need to register ethnic features in Latin American countries is, generally speaking, a relatively new process, generated by the variety of sociocultural dynamics existing in each country and by the reasons, specific to each country, that motivate this need. A conceptualization of ethnicity cannot therefore be applied in the same way to each national reality, which is reflected in the operationalization of each conceptualization in censuses. All this complicates efforts to establish standardized statistical criteria and procedures to allow the application of technically acceptable and politically admissible instruments, which could serve as a basis for comparing the situation of such groups in the different countries of the region. Despite all this, we believe it is necessary to continue progressing in this direction. We consider that a strategy which may allow relatively more secure conceptual progress is to begin by reviewing the most recent ideas on ethnicity, while using as a concrete reference the specific reality of a country that also has elements similar to those of other countries in the region. This is the case of Peru, where populations of Indigenous and African descent are found, albeit in very diverse proportions. Taking Peru as its reference, this paper first gives a brief presentation of the main current perspectives on ethnicity, and then discusses some of the implications of its operationalization in population censuses.
\end{abstract}

Words key: Ethnicity, population census, primordialism, constructivism, contextualism, Latin America. 


\section{INTRODUCCIÓN}

En los últimos años, el interés por la cuestión étnica en los países de la región se ha incrementado de manera progresiva debido a varios factores. Gran parte de la renovada atención puesta sobre el tema se deriva de la creciente movilización de los propios grupos de población considerados étnicos; en particular, los descendientes de pueblos originarios cuyo contacto con los estados-nación y las sociedades que los engloban se hace cada vez más intenso. Pero también responde a un cambio en la manera de conceptuar a las poblaciones originarias en cuanto a su relación con las realidades sociopolíticas que las contienen. En tal sentido, algunos autores consideran que son precisamente las dinámicas socioeconómicas y culturales de este creciente contacto lo que convierte a las "tribus indígenas" latinoamericanas en "minorías étnicas" al interior de las sociedades nacionales que las contienen. Así, a principios de la década de 1990, Urban \& Sherzer (1994) proponían que los diversos grupos indígenas latinoamericanos podían ser analíticamente ubicados en un continuo que iba desde las poblaciones aisladas o "no contactadas" hasta los grupos plenamente reconocidos como etnias y considerados como tales en el contexto del estado-nación. "Los grupos de las sierras andinas [...] parecen estar en el lugar más avanzado del continuo" (Urban \& Sherzer 1994: 5). Otros autores, como Jackson (1994), incluso proponen que dicho continuo responde en términos generales a la evolución de la relación histórica de los pueblos indígenas latinoamericanos con los estados de la región.

Por otra parte, esta transformación se ha ido reflejando también en las definiciones operativas para las políticas de desarrollo implementadas por las principales agencias internacionales de desarrollo y organizaciones mundiales. Así, por ejemplo, la primera declaración de políticas ante los pueblos indígenas y tribales del Banco Mundial, formulada en 1982, se centraba "en los grupos tribales considerados relativamente aislados y menos aculturados"(Plant, 1998: 31). Una nueva “directiva operativa" emitida en 1991 adopta una definición considerablemente más amplia sobre los pueblos originarios, abarcando diversos grupos sociales con una "identidad social y cultural diferenciada de la sociedad dominante que los expone a estar desaventajados en el proceso de desarrollo" (Plant, 1998). En forma complementaria, en esos mismos años instituciones como la Organización Internacional de Trabajo (OIT) y la Organización de Estados Americanos (OEA) señalaban que la continuidad de rasgos culturales y lingüísticos propios, así como la auto-identificación o reconocimiento de sí, son criterios fundamentales para establecer el carácter indígena de ciertos grupos sociales específicos (Deruyttere, 1997). Dichos rasgos constituyen a la vez parte de los criterios básicos de etnicidad, lo cual permite establecer una relación conceptual entre "situación indígena" y "situación étnica".

Por lo demás, varios países de la región han incorporado en sus constituciones políticas el reconocimiento del carácter multi-étnico y pluricultural de sus poblaciones, mientras que otros acogen derechos específicos hacia estos grupos también en sus constituciones (1). Esto se complementa con la recurrente constatación de que los

(1) Los países que reconocen el carácter multi-étnico y pluricultural de sus poblaciones son Bolivia, Ecuador, México, Nicaragua y Perú. Los que incorporan derechos específicos de carácter constitucional para pueblos indígenas que habitan en sus territorios son Argentina, Brazil, Guatemala, Panamá, Paraguay y Venezuela (Renshaw et al., 2001: 2). 
grupos étnicos figuran conspicuamente entre los sectores considerados propensos a situaciones crónicas de exclusión social, discriminación y desatención de necesidades socioeconómicas. Como parte de este reconocimiento, los ejercicios censales y demás prácticas estadísticas estatales en la región han ido incluyendo ítems que permitan la obtención de indicadores socioeconómicos referidos a los grupos que se encuentran en esta condición. Incluso recientemente se ha llevado a cabo dos encuentros regionales para reunir a especialistas, técnicos y funcionarios de los gobiernos de América Latina y del Caribe, junto con representantes de organismos multilaterales y líderes de comunidades y organizaciones de indígenas y afrodescendientes, para intercambiar experiencias al respecto de la manera en que se ha levantado información sobre los grupos étnicos en los ejercicios censales y demás procedimientos estadísticos de cada país (Memorias del Primer Encuentro Internacional Todos Contamos, 2002. También: II Encuentro Internacional Todos Contamos: Los Censos y la Inclusión Social (en prensa)). De este modo, se está llevando a cabo un conjunto de iniciativas a todo nivel para lograr un mejor conocimiento sobre la situación de estos importantes sectores poblacionales.

Todo lo mencionado refleja entonces un despliegue de esfuerzos cada vez más significativos para obtener mayor y mejor información de indicadores socioeconómicos de estas poblaciones, tanto para una más adecuada focalización y sostenibilidad de programas sociales del Estado y de las agencias de desarrollo, como para un progresivo reforzamiento de la identidad colectiva de estos grupos en relación con la sociedad que los engloba, y a su gradual empoderamiento a medida que se van conociendo mejor a sí mismos y sus líderes utilizan dicha información para su interacción con el sistema político nacional e internacional. En efecto, al establecer el nivel de presencia de estos grupos, se favorece su legitimización social en tanto se logra el reconocimiento de su situación y del lugar proporcional que le corresponde en la vida nacional, en la representación de intereses colectivos específicos, y en la atención a sus particulares necesidades.

Sin embargo, el reconocimiento de la etnicidad es en general un proceso relativamente nuevo, derivado a su vez de la variedad de dinámicas socioculturales que presenta cada país de la región. De ahí que la conceptualización de la etnicidad difícilmente puede ser aplicada por igual a cada una de las realidades nacionales, y la operacionalización de cada conceptualización refleja estas variaciones en el ejercicio censal. Todo esto complica los esfuerzos por establecer criterios y procedimientos estadísticos normalizados que habiliten la aplicación de instrumentos técnicamente aceptables y a la vez políticamente admisibles sobre cuya base se pueda comparar la situación de dichos grupos en los distintos países de la región. A pesar de todo, creemos que es necesario seguir tratando de avanzar en esta dirección. Una estrategia que puede permitir un avance conceptual relativamente más seguro es, en nuestra opinión, revisar las concepciones más recientes sobre etnicidad teniendo como referente concreto una realidad nacional específica pero que contenga elementos similares a la situación de otros países en la región. Es el caso del Perú, donde se encuentran presentes, aunque en proporciones muy variadas, poblaciones originarias y afrodescendientes. 
En este documento, y teniendo como referente a esta nación andina, haremos primero una sucinta consideración de las principales perspectivas actuales sobre etnicidad, para luego discutir las implicancias de su operacionalización en los ejercicios censales de población. Se trata de analizar, como nos ayudó a sintetizarlo la colega Elisabeth Cunin, algunas de las contradicciones que surgen de la tensión entre posiciones teóricas múltiples, desarrollos étnicos fluidos, procesos de identificación inestables y la exigencia de construir categorías fijas para los censos (2). Puesto de otro modo, esta reflexión implica también explorar el asunto de las relaciones entre los grupos étnicos y los Estados-nación de la región a través del ejercicio censal.

\section{CONCEPTO BÁSICO DE ETNICIDAD}

Es frecuente empezar la aproximación a un concepto complejo mediante la búsqueda del término en un buen diccionario, con el fin de adquirir una definición resumida y elemental. En nuestro caso, sin embargo, es interesante destacar que el Diccionario de la Lengua Española de la Real Academia Española todavía no incorpora el término "etnicidad", y sólo recientemente ha aceptado la palabra "etnia", derivada (a través del latín) del término griego "pueblo", bajo la acepción de "comunidad humana definida por afinidades raciales, lingüísticas, culturales, etc." (Diccionario de la Lengua Española). Cabe agregar que hasta hace poco figuraba en dicho diccionario únicamente el adjetivo "étnico", y se refería a lo "perteneciente a una nación o raza", pero también incluía la acepción de "gentil, idólatra o pagano" (Real Academia Española, 1984: tomo 1: 614). Resulta de todos modos significativo que la Real Academia Española, caracterizada por su conservadurismo en admitir nuevas acepciones al repertorio "oficial" de nuestra lengua, haya considerado oportuno incorporar el término "etnia". Esto se puede interpretar como un síntoma adicional de la creciente importancia que adquiere el tema étnico en la realidad contemporánea.

De ahí que los científicos sociales hispanohablantes hayan debido recoger aquel vocablo de otros idiomas, en los que el término "étnico" es más abarcante y está más cercanamente relacionado al fenómeno aquí discutido. Así, para tomar un ejemplo, en inglés el término ethnic (étnico) se refiere a lo "relativo a grandes grupos de personas clasificadas según un origen común de tipo racial, nacional, tribal, religioso, lingüístico, o cultural" (Merriam-Webster, 1987: 147). Además, en el inglés americano el término "étnico" es aceptado incluso como sustantivo: "miembro de un grupo étnico; especialmente, miembro de un grupo minoritario quien mantiene las costumbres, lenguaje, o creencias sociales de su grupo (Merriam-Webster, 1987)”. Por último, el citado diccionario incluye el término ethnicity con el significado de "cualidad o afiliación étnica", datando su incorporación en el año 1950 (Merriam-Webster, 1987).

En cada idioma el sentido de estos términos expresa en buena medida la experiencia social de su comunidad lingüística. Volviendo a nuestro ejemplo, el diccionario Merriam-Webster refleja la situación de las "minorías étnicas" en el

(2) Comunicación personal, 03-02-2003. Quisiera agradecerle aquí por todos los comentarios intercambiados al respecto, y en especial por sus sugerencias, las cuales me han servido para mejorar el contenido del artículo. 
repertorio lingüístico de los Estados Unidos. Ahí, hacia fines del siglo XX, la etnicidad era concebida comúnmente como un fenómeno minoritario, aunque últimamente las poblaciones de origen negroe iberoamericano están creciendo a un ritmo proporcionalmente mayor que la hasta ahora mayoría de origen anglosajón y europeo en general. Pero en países como el nuestro, la situación es prácticamente inversa, ya que en términos históricos la población de origen indígena fue mayoritaria hasta hace pocas décadas (3). En tal sentido, no cabría referirse a los pueblos originarios de nuestro país como "un grupo minoritario". Esto lo veremos con mayor detalle en el transcurso de nuestra exposición.

En cuanto a la historia del uso de términos “etnia” y “etnicidad”, Williams (1983: 119-120) nos dice que, en tiempos modernos y hasta el siglo XIX, connotaba el sentido de las características raciales atribuidas a los grupos humanos. Luego, en el siglo XX, se usó en las ciencias sociales para sustituir las connotaciones peyorativas del término "raza". Más recientemente, ha adquirido una connotación cercana a la noción de folclor, como en los estilos de vestimentas, músicas y comidas regionales. Su uso en el llamado Primer Mundo abarca ahora desde el sentido más académico en referencia a los grupos sociales, hasta su uso por la industria del turismo, la moda, y otras industrias culturales. No obstante, Billington et al. (1991: 87) advierten que si bien muchos científicos sociales del siglo XX han tratado de evadir los problemas asociados con el término raza mediante el desarrollo del concepto de etnicidad, este también se basa en una construcción ideológica con una historia específica de uso. Con esto queremos aclarar que el término "etnicidad" no necesariamente está más libre que el de "raza" de connotaciones ideológicas problemáticas, y que sólo un análisis histórico del uso social de estos términos permitiría comprender las diferentes connotaciones de su usanza entre los diversos individuos y grupos que lo han empleado (Stolcke, 1992).

En todo caso, pasaremos a revisar las principales conceptualizaciones de "etnicidad" en las ciencias sociales contemporáneas, dado que este trabajo no tiene el propósito de ahondar en la historia social del concepto. En síntesis, los grupos étnicos o etnias son identificados en términos de diferencias culturales básicas (4). Las etnias pueden concebirse en tal sentido como colectividades que existen dentro de una sociedad mayor y que se consideran o identifican a sí mismas como una comunidad distinguible frente al conjunto social, o que son identificadas y consideradas como diferenciadas por otras colectividades o por el resto de la sociedad precisamente por compartir a su interior tales características culturales.

(3) En 1940, las personas de origen indígena constituían el 46 por ciento de la población nacional, de acuerdo a los criterios usados en el empadronamiento del censo de ese año (véase: PERÚ 1944).

(4) Debemos aclarar que se está usando el término "cultura" en el sentido amplio que incluye el variado espectro de actitudes, comportamientos, prácticas sociales, símbolos, valores, y artefactos que caracterizan y distinguen a los humanos. De este modo, el concepto usado aquí no es valorativo y además va más allá de la educación formal o escolarizada, y también trasciende el sentido excluyente y elitista que ciertos grupos sociales tratan de imponerle al término en base a lo que consideran "refinado", "distinguido" o "cultivado". Nuestro uso del concepto cultura es propio de la antropología, por lo que incluye los símbolos y valores individuales o colectivos, y los artefactos que los "instrumentalizan" y le dan soporte técnico-material, que en su conjunto pueden caracterizar a un grupo humano o estrato social específico y distinguirlo de otros. 
$\mathrm{Al}$ respecto, Roland Breton, quien es uno de los más citados estudiosos del tema, expresa esta situación con cierto tono crítico:

Para muchos de nosotros las etnias son las otras [colectividades]. Y la división académica entre el campo [de estudio], el vocabulario y los métodos de [la sociología y la antropología] reflejan también esta división radical entre La Sociedad (la buena sociedad, normal, el centro del mundo) y los grupos étnicos: marginales, periféricos, arcaicos, atrasados y en vías de extinción, propios de una cierta anomalía y por lo tanto de un enfoque especial (Breton, 1983: 17; itálicas en el texto original).

En este sentido, agrega el autor citado, el uso del término "etno" como prefijo aparece en la denominación de disciplinas científicas relativamente recientes que estudian aspectos específicos de las sociedades no occidentales, como sus sistemas de conocimiento, comunicación, expresión estética y valores: etnobotánica, etnolinguiística, etnomusicología, etnofilosofía.

La creciente atención que la noción de etnicidad suscita no está circunscrita al mundo académico. El prefijo "etno" ha rebosado más recientemente el dominio científico, llegando a ser aplicado para caracterizar ciertos productos y servicios de industrias culturales orientadas al mercado global. Se ha observado últimamente el crecimiento del interés en lo "étnico" también en públicos más amplios, pero bajo un sesgo de tipo recreativo. Así, al incrementarse en los últimos tiempos la promoción del llamado turismo ecológico y el "de aventura", se ha incorporado a estos circuitos excursiones para presenciar las costumbres de grupos culturales "exóticos" de países o lugares que para dichos públicos son de alguna manera "remotos". En el Perú, por ejemplo, se puede hacer visitas turísticas a localidades de los principales grupos étnicos: hospedaje en pueblos originarios altoandinos, visitas a pueblos amazónicos, y el "turismo étnico negroide".

\section{CARACTERÍSTICAS USADAS PARA DISTINGUIR GRUPOS ÉTNICOS}

Desde el punto de vista endógeno, sin embargo, los segmentos o grupos étnicos se identifican a sí mismos como poseedores de un origen común y portadores de elementos, rasgos, o características importantes de una cultura propia o común; y cuyos miembros además participan en actividades y prácticas grupales que sirven para mantener y reproducir o recrear dichas características culturales. Para Breton (1983: 12), éste constituye el sentido amplio del término: "un grupo de individuos unidos por un complejo de caracteres comunes [...] cuya asociación constituye un sistema propio, una estructura esencialmente cultural: una cultura. [La etnia] es la comunidad, unida por una cultura particular". La etnicidad implica, en otras palabras, "una continuidad cultural intergeneracional y colectiva" o "el carácter o la naturaleza propia de uno [...] que se deriva de la inmersión en esa continuidad cultural" (Fishman, citado por Villarreal et al.: 359). Hay varias perspectivas sobre la etnicidad, pero todas ellas básicamente comparten en atribuirle ciertas características. A continuación revisaremos brevemente dichas características, luego de lo cual expondremos resumidamente la manera en que las principales corrientes de análisis social sobre etnicidad conceptualizan tales características. 


\section{1. Idioma}

Existen distintas perspectivas con respecto a cuál de los mencionados elementos es el más importante para diferenciar a un grupo étnico en su relación con el resto de la sociedad en la que está inmerso. Desde algunas concepciones de etnicidad, el idioma es el rasgo principal que caracteriza al grupo étnico:

En sentido estricto la palabra etnia puede designar a un grupo de individuos pertenecientes a la misma lengua materna. [En] estos casos etnia es equivalente a grupo lingüístico, o grupo etno-lingüístico, es decir, lo que los lingüistas designan como grupo de lengua materna o g.l.m. (Breton, 1983: 11-12; itálicas en el original.)

Entendida así, la etnia se vuelve equivalente a una colectividad culturalmente indiferenciada a su interior, en tanto dicha perspectiva asume que el idioma es el principal vehículo de cohesión cultural y transmisión de las visiones colectivas del mundo e imaginarios sociales:

"En este sentido, la palabra [etnia] es adecuada para designar unos conjuntos reales generalmente bastante homogéneos de [personas] quienes se asemejan y presentan unos rasgos culturales comunes que se manifiestan a través del uso de una lengua propia. (Breton, 1983: 12)."

El lenguaje, según los estudiosos sociales, es no sólo un medio de comunicación. Es sobre todo un elemento central de la cultura y del proceso de socialización. A través de la lengua el grupo expresa su propia cultura, su identidad social, porque el idioma está íntimamente ligado a los procesos mentales e ideológicos, a la percepción del mundo interior y exterior, la naturaleza y la sociedad (Stavenhagen, 1990: 108). Cada lengua es el resultado dinámico del continuo proceso de adaptación y manejo del entorno natural y social del grupo. Así, varios autores consideran que un grupo cultural que pierde su lengua propia está en proceso de desaparecer como grupo étnico: es una comunidad cultural en vías de extinción.

Es necesario tener en cuenta que el proceso de colonización europea por lo general degradó culturalmente los idiomas de los grupos indígenas al considerarlos meros "dialectos", término que connota una situación de inferioridad cultural porque implica que no es un lenguaje estructurado y plenamente desarrollado. De este modo, en la opinión pública contemporánea existe todavía la imagen de que los grupos indígenas hablan sólo "dialectos" y no lenguas, con lo cual se perpetúa una percepción de inferioridad cultural de estos grupos. Aunque lingüísticamente esto no sea correcto, hay una intención política detrás de esta subvaloración de las lenguas aborígenes, porque de esta manera se justifican o legitiman muchas veces las políticas gubernamentales de aculturación y asimilación, especialmente en cuanto a la educación monolingüe en el idioma nacional. Es así que se ha debatido mucho sobre la alternativa de que los grupos indígenas sean alfabetizados en su propia lengua, y diversos sectores de intelectuales y de los propios indígenas plantean la educación inicial bilingüe (en el propio idioma del grupo y en la lengua nacional predominante) como una reivindicación cultural. 


\section{2. Antepasados comunes}

El uso del idioma como criterio de diferenciación étnica, sin embargo, tiene el inconveniente de apoyarse en un noción un tanto abstracta de "lengua propia", ya que pasa por alto las diferencias internas que existen en los amplios grupos humanos que poseen la misma lengua materna. En todo caso, habría que precisar mejor el aspecto lingüístico en términos de la existencia de sociolectos al interior de un mismo idioma. De ahí que se busquen otras características para distinguir a grupos sociales en términos étnicos. Entre ellas está la de tener antepasados comunes, lo que implica percibir y atribuirse una historia u origen compartido como grupo:

La etnicidad [...] estaría relacionada con una colectividad de la que no sólo se entiende que tiene una "profundidad histórica" [Fishman 1985: 4], sino más específicamente, que comparte unos orígenes ancestrales y, consecuentemente, unas cualidades o naturaleza que se derivan de ellos. El hecho, por tanto, de que un individuo se cuestione en qué medida puede ser partícipe de una determinada cultura o sociedad, enlaza con el fenómeno de que este sujeto pueda ser, de alguna manera, una prolongación de dicha etnicidad, es decir, el grado en que el sujeto ha quedado impregnado por la etnicidad o el grado en que ésta tiene que ver con sus sentimientos y percepciones sociales, con su comportamiento, etc. (Villarreal et al.: 359-60).

La atribución de antepasados comunes no equivale a una percepción biológica sino más bien cultural, remitiéndose por lo general a un pasado no necesariamente mítico o muy antiguo, pero sí mínimamente remoto como para hacer difícil por lo general establecer para cada miembro del grupo una línea directa con los primeros antepasados que se atribuyen. Todo esto se relaciona a la mantención y recreación de una memoria colectiva que se proyecta como "historia étnica" por lo general celebratoria y que en grupos minoritarios y socialmente subordinados ayuda a la vigencia de su identidad cultural y contribuye a su solidaridad interna.

\section{3. Ocupación prolongada de espacio geográfico}

Otro rasgo importante es el de la ocupación prolongada de un determinado espacio geográfico y por ende su adaptación socioecológica a dicho espacio. En este sentido, el concepto de etnicidad se relaciona con el de nacionalidad, sobre todo cuando el rasgo de ocupación territorial se junta al de los antepasados en el sentido que acabamos de ver arriba. Al mencionar a los elementos generales en que se fundamenta la estructura étnica, por ejemplo, Breton se refiere así al territorio:

"Es el marco físico en donde la etnia se ha fijado, e incluso muchas veces donde se ha constituido a partir de elementos de procedencia diversa. La etnia se ha adaptado a este medio natural y lo ha transformado en menor o mayor grado para la utilización de sus recursos. Cuanto más desarrollada, sofisticada y exigente es la economía, más modifica el marco ecológico, más "humaniza" el paisaje. Cuanto más densa es la ocupación del territorio más profundas e irreversibles son estas transformaciones. [...] Sean cuales 
fueren la forma de ocupación del suelo y la antigüedad de la implantación, cada etnia tiene una noción precisa de sus relaciones con el territorio, de la delimitación de su jurisdicción y de los eventuales repartos con las otras etnias [...]." (Breton, 1983: 46, 49)

Stavenhagen (1990: 100), por su parte, señala que el problema de la ocupación territorial y explotación de los recursos es la principal reivindicación que los grupos indígenas reclaman en nuestros tiempos, sobre todo cuando el estado o las empresas transnacionales tratan de explotar los recursos naturales de las tierras habitadas por ellos. Se trata así de defender los derechos de los pueblos indígenas sobre los territorios que tradicionalmente han sido ocupados por estos grupos. Esto se debe a que el territorio no sólo representa la fuente principal de recursos para la subsistencia económica de estos grupos, sino que además es la base de su identidad social y cultural. Es la tierra de sus antepasados, el lugar de los vínculos religiosos y míticos con el pasado y con lo sobrenatural, y es el entorno en el cual han adaptado y desarrollado su cultura y estilos de vida característicos mediante un largo proceso de interrelación con la naturaleza.

"Para los nativos [de la Amazonía], la Selva no es un medio de inversión y de lucro. Para ellos, la Selva es su medio, su hogar, su fuente única de abastecimiento y creación cultural. Privarlos de su territorio [...] es más que quitarles su medio de trabajo: es también privarlos de su vida misma. [Estas poblaciones] han establecido con su medio relaciones de complementariedad. La eliminación de la Selva conlleva la eliminación de la cultura, la sociedad y el individuo, puesto que de ella se nutren física y culturalmente." (Chirif, s.f.: 13)

La cita precedente es ilustrativa del modo en que en nuestro medio este criterio ha sido adoptado por diversos investigadores sociales. Así, se considera que existen rasgos básicos de las culturas aborígenes derivados de este proceso centenario de ocupación territorial, desde los aspectos materiales hasta los ideológicos y espirituales. En tal sentido, cuando en la actualidad se habla de los grupos amazónicos, la ocupación territorial constituye uno de los elementos para demarcar y sustentar la existencia social de estos grupos, e incluso para considerarlos como "naciones":

"Un [...] punto importante [con respecto al pueblo amazónico amuesha] es el concepto de territorialidad del grupo nativo. Las sociedades nativas eran, hasta hace poco tiempo, naciones independientes con un mismo lenguaje y una misma visión del mundo, unidos por una red de relaciones sociales y económicas. [U]na de las bases importantes de esta nacionalidad es el reconocimiento grupal tácito de un territorio común; al interior de [sus límites] reside "nuestra gente" o, como dicen los amuesha, "nosotros gente". Este concepto de territorialidad [desde el punto de vista de los nativos es reclamado por] haber recibido de su Dios el derecho de usufructo [de la tierra que ocupan]. La tradición oral confirma este derecho a usufructuar un territorio particular [...]." (Smith, s.f.: 173)

Vemos que este rasgo de la etnicidad se entrelaza, por otra parte, con el aspecto de la definición de la nacionalidad. En diversas partes del mundo donde existen conflictos étnicos de carácter nacional, los pueblos que aspiran a lograr autonomía 
política por lo general incluyen entre sus reivindicaciones el control sobre cierto territorio que consideran una base histórica para su reclamo independentista. En principio, no se puede concebir un estado-nación sin derechos soberanos sobre un territorio. De ahí que un reclamo constante de los grupos separatistas es tener derechos particulares sobre un determinado territorio que se reclama propio por su ocupación continua desde tiempos inmemoriales, lo que para algunos autores es una característica inherente a los grupos humanos:

"Dentro de los estados actuales son numerosos los movimientos étnicos que reivindican la delimitación un territorio, autónomo o no: se trata de la manifestación de la natural tendencia de cada grupo a señalar su lugar en la tierra. [Tal sentimiento está] basado en el instinto atávico del territorio que el hombre comparte con el animal [...].” (Breton, 1983: 50)

\section{4. "Raza"}

Es importante mencionar que cuando es la sociedad mayor la que define o identifica grupos étnicos a su interior, muchas veces se resaltan los rasgos externos o más visibles que son comunes a los miembros de un grupo específico. Por lo tanto es necesario tratar de aclarar algunos problemas con el término "raza", ya que constituye precisamente uno de los rasgos más aparentes de diferenciación étnica y de discriminación racial. La "raza" se considera usualmente un factor biológico más que cultural, y muchas veces se ha empleado ciertas características fisiológicas de los individuos para identificarlos o clasificarlos según su "raza". Sin embargo, algunos de estos rasgos fenotípicos tales como el pigmento de la piel o la forma y color de los ojos no tienen valor en sí mismos, y sólo adquieren importancia en las relaciones humanas cuando en una sociedad determinada se les atribuye significado o valor social y cultural.

Es así que la categoría de "raza" (en tanto rasgos fisiológicos y/o herencia biológica) también ha sido utilizada históricamente para denotar a ciertos grupos sociales, y se relaciona con la noción de etnicidad en tanto mediante ella se tiende a asumir que el grupo tiene un origen común al nivel más básico y esencial; es decir, a un nivel biológico apenas por encima de la diferencia de especie animal. Por otra parte, las visiones más extremas de raza pretenden asociar la herencia biológica con determinadas costumbres y estilos de vida (vivienda, vestimenta, comida), actitudes y comportamientos (v.g., personalidad "flemática", "colérica", o "sanguínea"), atribuyéndolas de modo generalizado al conjunto de miembros así caracterizados. Es a partir de este tipo de visiones que surge el racismo como ideología que justifica tratos discriminatorios de diverso tipo. Pero a la vez, este rasgo de diferenciación social puede tener un efecto aglutinante para los discriminados:

El racismo es una reacción del grupo dominante e incluye la idea no sólo de que hay culturas distintas y subordinadas, sino que éstas son además exógenas [...]. Pero el racismo también puede ser utilizado por un grupo subordinado de diversas maneras [...], incluso para agruparse y ofrecer resistencia ante el grupo dominante. (Billington et al., 1991: 99). 
Es necesario agregar aquí que algunos autores establecen una diferencia básica entre etnicidad y "raza" en términos de la capacidad del grupo de identificarse como tal o de ser identificados por el resto de la sociedad. Así, mientras que los miembros de grupos étnicos se ven a sí mismos como grupo porque comparten una identidad colectiva, la identificación de los "grupos raciales" es adscrita por personas fuera del grupo, y no necesariamente implica un sentido de identidad compartida más allá de la de ser objeto de similares percepciones o prejuicios (Renshaw et al., 2001: 9).

En cuanto a la perspectiva antropológica actual sobre la raza como factor diferenciador, la mayoría de científicos sociales ha abandonado la base estrictamente biológica para la clasificación de grupos sociales e incluso de "grupos raciales". Entre los argumentos sociológicos presentados para refutar la base fisiológica de la categoría racia, destacan los siguientes:

- las categorías raciales varían mucho alrededor del mundo, ya que en cada país hay diferencias y matices (aparte de terminologías) que no coinciden entre sí;

- sus definiciones son fluidas incluso dentro de un mismo país, existiendo una serie de gamas que no son fácilmente ubicables en las categorías existentes (Martin \& Nakayama, 1997: 73-74).

Pero también hay argumentos genotípicos cuestionadores de la diferenciación biológica de tipo "racial" que han empezado a surgir en los últimos lustros en tanto se ha ido descifrando el "mapa genético" humano:

"Con la vasta expansión del conocimiento científico [en el siglo XX], ha quedado claro que las poblaciones humanas no son grupos biológicamente distintos claramente demarcados. La evidencia del análisis genético (p.ej., el ADN) indica que la mayor diferencia física, cerca del 94\%, yace al interior de los así llamados grupos raciales. Las agrupaciones geográficas 'raciales' convencionales se diferencian unas de otras sólo en un $6 \%$ de sus genes. Esto quiere decir que hay más variación al interior de los grupos 'raciales' que entre ellos. [...] A través de la historia cuando distintos grupos han entrado en contacto, se han entrecruzado. El continuo compartir los materiales genéticos ha mantenido a toda la humanidad como una única especie." (American Anthropological Association, 2002b) (5)

Es así que los científicos sociales ahora se remiten más bien a una aproximación social para concebir la raza, entendiendo que las categorías raciales como "Blanco", "Indio", "Amarillo" o "Negro", por ejemplo, son construidas en contextos históricos y sociales específicos. Algunos autores incluso hablan de "razas sociales" en contraste a las comúnmente percibidas "razas biológicas”, según señala Stavenhagen (1990: 2-3). Un ejemplo cercano a esta aproximación social es la propuesta por Wade (1997) y retomada por Flórez, Medina \& Urrea (2001:3-4), que plantea una “definición objetiva”

(5) Esta es la posición oficial de la Asociación Norteamericana de Antropólogos (American Anthropological Association) sobre el asunto de la "raza", acordada en 1998, y "representa en términos generales el pensamiento contemporáneo y postura académica de la mayoría de antropólogos" (American Anthropological Association, 2002b). Véase también: American Anthropological Association, 2002a. 
de la raza como un conjunto de construcciones sociales basado en variaciones fenotípicas como el color de la piel, tipo de cabello, y rasgos faciales y anatómicos.

Pero también hay otros conjuntos de elementos que son usados para diferenciar a los grupos sociales en términos "externos" como grupos étnicos, mediante la atribución por asociación de ciertas habilidades para desempeñar ciertas prácticas laborales u ocupaciones, o también de conocimiento detallado en el manejo del entorno físico según una lógica de adaptación cultural a determinados ecosistemas. Un criterio relacionado con el anterior y que ciertos autores establecen para la condición étnica es en conexión a ciertas actividades distinguibles histórica y geográficamente, o por las características del entorno. En términos de ocupaciones, por mucho tiempo se ha identificado en nuestro país al campesino serrano como “indio". Llevando esta apreciación a un nivel de generalización mayor, Ribeiro (1979) analiza las diferencias al respecto entre el campo y la ciudad, postulando que:

"la condición campesina, al permitir a los hombres conservar por largos periodos sus tradiciones, preserva sus caras humanas o étnicas originales. En las ciudades, por el contrario, los conquistadores se suceden, las novedades se difunden rápidamente, todo cambia, incluyendo la propia identificación étnica de la población.” (Ribeiro, 1979: 2)

Ahora bien, según este autor, la condición campesina en la población rural aborigen de nuestros países es crucial para la identidad étnica, porque permitiría que los rasgos étnicos anteriores a la estratificación de clases sociales se preserven en el campo. Según el mismo Ribeiro (1979: 4), los indígenas pierden en las ciudades sus rasgos étnicos. La gente de origen rural se convierte en "una mera fuerza de trabajo, sin lengua, ni costumbres, ni voluntad propias. Despojados de sí mismos, despersonalizados de sus características culturales, ellos podían ser transfigurados étnicamente" (6).

En una apreciación sobre la antigüedad aproximada del fenómeno étnico el citado autor considera, por lo demás, que la condición étnica es anterior a la de campesino o de trabajador manual agrícola (como lo es en general en la humanidad), porque "las etnias y los conflictos inter-étnicos son muy anteriores a las clases ya que las sociedades estratificadas tendrán, cuando mucho, seis mil años de existencia, mientras que las etnias vienen de tiempos inmemoriales." (Ribeiro, 1979: 16)

\section{5. Identidad étnica}

Para algunos analistas de la situación reciente en países andinos, la conciencia de la propia identidad étnica es un factor básico de la etnicidad. Degregori (1993), por ejemplo, considera que "es necesario tomar en cuenta la dimensión subjetiva por la cual una población dada se autopercibe como etnia". Según esto, la autoconciencia de su

(6) Ribeiro, sin embargo, ofrece un análisis un tanto complejo frente a todo este proceso, porque también reconoce que en la actualidad ciertos rasgos étnicos de las poblaciones rurales pueden sobrevivir a los procesos de modernización y urbanización, incluso en ciudades céntricas. Aunque en el trabajo citado Ribeiro no llega a explicar del todo esta nueva dinámica, afirma que hay una situación reciente en que se observa el mantenimiento de características étnicas más profundas y duraderas en relación con la condición de clase que se adquiere en el proceso migratorio a las ciudades. 
idiosincrasia, o al menos cierta percepción del propio grupo sobre su "otredad" o su peculiaridad, se presentaría como rasgo importante en la caracterización de movimientos sociales y culturales asociados a la etnicidad. Otros analistas, en cambio, ven la etnicidad como un rasgo inconsciente o subconsciente, de modo que no siempre se presenta en forma auto-reflexiva, y que sólo en determinadas coyunturas se "activa" y se vuelve conciente para el propio grupo. De ahí que se requiera una situación de contacto intercultural para que la etnicidad aflore.

Se puede notar entonces que la determinación de la etnicidad implica varios aspectos, y su atribución a un grupo específico requiere, según cierta perspectiva, el análisis de los dos niveles más aparentes de su existencia: lo que se considera el nivel "objetivo" (es decir, un criterio de percepción externo al grupo), y el "subjetivo" (es decir, un criterio desde los sentimientos y percepciones al interior del grupo):

"Lo único que permite establecer cuáles son los criterios de identificación más válidos en cada caso es el examen de cada grupo étnico [...], tanto objetivamente, a los ojos del observador, como subjetivamente, en la conciencia de los interesados." (Breton, 1983:13)

Esta idea ha sido expresada de forma similar en tiempos más recientes por Urban \& Sherzer (1994) al señalar que, desde un punto de vista objetivo, los grupos étnicos son grupos de interés dentro del ámbito de una sociedad mayor; pero subjetivamente, sin embargo, su situación es diferente. "Si queremos entender el curso de eventos venideros, necesitamos apreciar la auto-percepción subjetiva del grupo étnico — cómo el grupo ve su propia situación actual— así como sus circunstancias objetivas entendidas en términos de intereses, recursos y competición" (Urban \& Sherzer, 1994: 5). Para tratar de entender mejor a los grupos étnicos en términos más amplios, los analistas sociales han desarrollado diferentes visiones sobre las dinámicas de formación y desenvolvimiento de estas colectividades. A continuación veremos sus conceptos básicos.

\section{CONCEPTUALIZACIONES BÁSICAS DE LA DINÁMICA DE ETNICIDAD}

Los rasgos étnicos expuestos en la sección anterior pueden estar combinados, y puede haber más de un rasgo compartido por el grupo (7). Estas combinaciones pueden, incluso, variar en el tiempo. Tanto los propios grupos étnicos, como la sociedad mayor que los envuelve, darán más importancia a uno o varios de estos rasgos en distintos momentos de su historia según la situación en que se encuentren y la dinámica relacional que se entable entre ambos conjuntos. En todo caso, es poco usual que un grupo étnico se perciba a sí mismo o sea percibido por otros como poseedor de todos estos elementos distintivos a la vez o en un mismo momento. Por lo general, en cada coyuntura histórica se usa uno o dos de estos rasgos diferenciadores como los más representativos o simbólicos de su identidad colectiva (Breton, 1983; Riggins, 1992). Aunque los intentos de comprensión del fenómeno de la etnicidad tienen ya muchas décadas (Williams, B.,

(7) A modo de ilustración, en el caso de los pueblos originarios de la Amazonía el uso de un idioma específico se combina conla ocupación histórica de un territorio específico y la adaptación ecológica del grupo a dicho territorio: se habla así de los grupos etno-lingüísticos amazónicos. 
1989) aquí vamos a exponer sólo las perspectivas más recientes que existen en cuanto a la conceptualización de la dinámica sociocultural que propicia dicho fenómeno (Friedman, 1993;Hechter, 1986; Kellas, 1991; Nagi, 1992; Young, 1993; cf. Stavenhagen, 1990). Estos parecen ser los principales discursos teóricos de análisis social que actualmente predominan en la mayoría de estudios sobre el tema, aunque no siempre son manifestados explícitamente cuando se discute el fenómeno. De ahí que, al intentar hacerlos más evidentes, podemos entender mejor las implicancias de adoptar uno u otro punto de vista a efectos de su operacionalización en el próximo ejercicio censal. Debemos aclarar, por otra parte, que dichas perspectivas básicas no siempre se expresan en forma pura o extrema, sino que por lo general prima una de ellas, complementada con elementos de las otras.

El elemento de parentesco, real o simbólico, resulta importante en la existencia de los grupos étnicos. Así, se afirma que estos grupos están conformados por conjuntos de familias, las cuales otorgan poder sobre la generación de los mayores de modo que ejercen control político sobre la asignación de las tierras "tribales" y sobre la interpretación de la cultura y tradiciones del grupo. Al darle poder a los mayores, los grupos étnicos crean un marco político que hace plausibles las expectativas de que los más jóvenes del grupo efectivamente cumplirán con sus obligaciones y responsabilidades ante el resto del grupo (Bates, 1999: 10-11). Por otra parte, aunque la pertenencia al grupo étnico es una prerrogativa que puede ser activada individualmente, dicha pertenencia está restringida por la membresía de tipo familial (Bates, 1999: 4). Ahora bien, la sustancia de esta prerrogativa, como la de la mayoría de derechos, es negociable incluso dentro de las agrupaciones étnicas (8). Como bien lo ha estudiado la antropología, los lazos familiares entre los seres humanos no son únicamente consanguíneos o carnales: también hay vínculos de compadrazgo y parentescos políticos y matrimoniales.

\section{1. Primordialismo}

Una de las principales perspectivas sobre la etnicidad se conoce como el "primordialismo", y sus seguidores resaltan la predominancia de lo que denominan "afiliaciones primordiales". Estas son vistas como lazos afectivos derivados del sentimiento intragrupal que caracterizaría a todos los grupos humanos, que producen la relativa hostilidad y hasta rechazo que se siente frente a los que no son del grupo, a los "otros"; siendo todos estos rasgos referidos a los elementos subjetivos y sicológicos en general que conforman las identidades étnicas (Stavenhagen, 1990: 9). Esta posición sostiene que la etnicidad es el reflejo de "identidades primordiales"; por lo tanto, se ve como habiendo existido desde el principio de la historia registrada o aun desde los propios orígenes de la humanidad. Algunos autores, según refiere Young (1993: 23), llegan incluso al extremo de sostener que la conciencia de afinidad grupal es tan profunda y antigua que está impresa en el código genético humano, como resultado de los muchos milenios de existencia prehistórica cuando era crucial para la supervivencia,

(8) “Como frecuentemente se señala, hay una cualidad plástica en la etnicidad; no es rígida, como a veces argumentan quienes enfatizan el papel del primordialismo o de la tradición”. (Bates, 1999: 4, nota p. de p.). 
la filiación basada en el reconocimiento de los miembros de la misma especie frente a otras, y a su interior para la participación en la reproducción del grupo inmediato. Es supuestamente de este contacto constante y más cercano de donde nace la primigenia "comunidad" humana, la cual es considerada además esencial a la naturaleza de la persona social y supuestamente presente en todas las conformaciones de grupos que puedan existir como parte de la especie humana evolucionada.

Desde esta perspectiva, los sentimientos étnicos se conciben como vínculos que unen a los grupos de manera enigmática, racionalmente inexplicable, y se considera la etnicidad como un componente esencial y permanente de la "naturaleza humana", como parte del comportamiento básico o impulso instintivo elemental de la humanidad (Hechter, 1986: 13; véase también Geertz, 1973; Van den Berghe, 1978; Stack, 1986; Kellas, 1991). Se trata, así, de darle alguna explicación a la poderosa e inveterada carga afectiva, a la intensa cualidad emocional que está subyacente en gran parte de los comportamientos étnicos (Young, 1993: 22).

Sin embargo, los "primordialistas" tienen varias limitaciones. En cuanto generalizan la caracterización de una "esencia humana" a verdades universales atemporales hacen que, precisamente este supuesto carácter universal, no ayude mucho al tratar de entender o explicar las diferencias locales o rasgos étnicos particulares que existen alrededor del mundo (Kellas, 1991: 8). Por otra parte, si nos ubicamos exclusivamente en este perspectiva, tampoco se puede comprender por qué existe una variación a través del tiempo en la intensidad de los sentimientos étnicos, al punto de desaparecer por momentos y reaparecer con inusitada fuerza en otras coyunturas históricas.

En todo caso, como adelantábamos más arriba, un factor importante en la dinámica social de la etnicidad es que muchas veces los rasgos étnicos se vuelven notorios o socialmente relevantes como resultado del contacto de un grupo étnico con otros grupos diferentes, o también como resultado de la naturaleza de las relaciones que vinculan ciertos grupos sociales específicos con el Estado al que políticamente pertenecen o del cual forman parte (Stavenhagen, 1990: 9). Así, aunque por lo común se piense que la etnicidad es un rasgo inalterable de la vida y que está determinado desde el nacimiento, otras posiciones del análisis social contemporáneo tienden a concebir la etnicidad como una construcción social. Aunque la identidad étnica obviamente consiste hasta cierto punto de características adscritas (estatus determinados por el nacimiento), es también en parte un logro tanto a nivel individual como grupal.

\section{2. Perspectiva constructivista}

Lejos de constituir una constante primordial incuestionable, para otras perspectivas de análisis la etnicidad puede ser "re-descubierta" o "reivindicada". Más aún, no sólo los grupos culturales desaparecen por asimilación o "aculturación” y "transculturación”, sino que además se están formando constantemente nuevos grupos étnicos (Marger \& Obermiller, citados en Riggins, 1992: 2). La etnicidad sería así un proceso dinámico que requiere de al menos dos grupos interactuantes, ya que el aislamiento social tiende a inhibir la percepción de los rasgos comunes endógenos al grupo y la de su particularidad 
cultural. La etnicidad implica, desde esta perspectiva, cierta capacidad de elección de un individuo de identificarse con un grupo, así como la reacción frente al grupo de parte de los que no pertenecen a él (Riggins, 1992: 2). Entonces, no se trata de una experiencia social constante o uniforme ni para los individuos ni para los grupos. Más bien, es un fenómeno variante, procesal (9) y emergente, y por lo tanto se manifiesta en formas diferentes y con grados diversos de intensidad en distintos contextos sociales (Marger \& Obermiller, citados en Riggins, 1992: 2).

En este sentido, hay una visión de etnicidad denominada "constructivista". Según Young (1993), la perspectiva constructivista está influida por el discurso postestructuralista. De acuerdo a esto, el grupo étnico es sobre todo una "comunidad imaginaria", de modo análogo a la concepción de Anderson (1983) sobre la nación. Se ve así al grupo como una colectividad que debido a su tamaño no puede establecer permanentemente relaciones directas, cara a cara, aunque sus miembros desarrollan y comparten los sentimientos propios de grupos primarios y se imaginan ligados entre sí por vínculos semejantes a los que mantienen unidos a los grupos primarios (familia, vecindad, pequeñas colectividades que comparten un hábitat reducido y que mantienen contacto directo cara a cara, permanente y cotidiano). Así, para los constructivistas lo que debe ser analizado no es lo que motiva la actividad del grupo étnico, sino la problemática étnica debe ser referida a la propia existencia del grupo. Se debe establecer la génesis de símbolos en el ámbito de los imaginarios colectivos. Por otra parte, se ve a las personas "como los agentes de su propia historia, pero que se desenvuelven dentro de diversos contextos y límites materiales, institucionales, e ideológicos" (Quirin, 1993: 201).

Esta visión de la etnicidad pone énfasis en el carácter creativo e imaginario de la construcción del grupo mediante la construcción de la identidad étnica. Se le atribuye entonces mayor capacidad a los individuos de definir y manipular sus posiciones sociales. La etnicidad es así una posición estratégica que asumen los individuos y los grupos en un determinado momento de su desenvolvimiento social, pero está en constante flujo y redefinición. Por lo tanto, el sentimiento étnico debe analizarse en cada coyuntura histórica, incluyéndose tanto al grupo de intermediarios culturales o activistas que tratan de aglutinar ideológicamente al grupo étnico, como a los propios individuos del grupo en tanto necesitan apegarse a ciertos valores que son concebidos como tradicionales para darles seguridad especialmente en momentos de profundo cambio sociocultural. La conciencia étnica está siendo socialmente construida desde los individuos en sus interacciones cotidianas, en las cuales estos se definen y redefinen a sí mismos constantemente. A través de múltiples mecanismos, y mediante dinámicas complejas, la conciencia étnica va acomodándose a los diversos niveles de interacción social, desde los grupos más pequeños hasta el nivel estatal de relaciones interétnicas.

En cuanto al énfasis en lo relacional, las nuevas corrientes de análisis social consideran que no se puede hablar de un grupo étnico sin considerarlo en el marco de un sistema de relaciones étnicas; no existe un grupo étnico aislado o en sí mismo, aunque durante muchos años las ciencias sociales hayan concebido así a estos grupos

(9) Del inglés processual. 
(Stavenhagen, 1990: 14). Es más, se ve la etnicidad como algo que se construye no sólo en cada momento y que cambia en relación con el contexto macrosocial o histórico, sino que además se percibe como algo que puede variar en un mismo individuo hasta en los niveles de relación contextual microsocial. Estas nuevas corrientes de análisis social han enfatizado especialmente la multiplicidad y la fragmentación de identidades sociales, a la vez que postulan la capacidad individual de poner en acción selectiva y pragmáticamente los diversos repertorios culturales que manejan los individuos, permitiendo desarrollar la perspectiva relacional. Esto quiere decir que una misma persona puede adoptar diferentes posiciones étnicas según la interacción social que está teniendo con diferentes personas al interior de una misma sociedad. Frente a algunas personas, este individuo puede ser visto como miembro de un grupo étnico específico, mientras que frente a otras su estatus étnico puede cambiar para ser puesto en una relación de subordinación jerárquica. Resulta siendo en resumen una dinámica de autoidentidad étnica "negociada" o "tranzada".

Quiere decir entonces que, desde otras perspectivas de análisis, muchos de los rasgos constitutivos de la etnicidad no serían necesariamente inmutables o perennes. Estos rasgos pueden ser manipulados o reforzados de acuerdo al momento histórico y al contexto social, para distinguirse o ser distinguido como grupo. En tal sentido, los propios rasgos étnicos son objeto de disputa para obtener su control, tanto desde el interior de los grupos como desde los otros grupos interactuantes y del conjunto social en el que están inmersos. La etnicidad depende entonces de la construcción social de la diferencia, en la cual los factores biológicos pueden jugar un papel significativo pero no imprescindible (Billington et al., 1991: 87). Por otra parte, el concepto de grupo étnico no es siempre equivalente al de minoría étnica o social, ni tampoco al de grupo social o políticamente subordinado. Los grupos dominantes también tienen rasgos étnicos y, por otra parte, los grupos subordinados pueden ser numéricamente mayoritarios aunque políticamente estén bajo el dominio de una minoría étnica. Por lo tanto, hay que distinguir la etnicidad de las relaciones sociales y de poder entre los grupos dominantes y los grupos étnicos.

\section{3. Perspectiva contextualista/situacional}

Un aspecto que algunos autores destacan acerca de la "condición étnica" de un grupo social es que se trata del resultado continuo de una dinámica "situacional", en tanto su particularidad cultural, o "inventario de rasgos culturalmente distintivos, ha sido producido en gran medida como resultado de la interacción con otros sectores de la sociedad en la que el grupo está inmerso" (Jackson, 1994: 131). Por otra parte, esta interacción con el resto de la sociedad lleva a desarrollar por lo general un fuerte sentimiento de solidaridad al interior del grupo, lo cual a su vez requiere que el grupo "mantenga un control activo sobre los elementos culturales y simbólicos que constituyen los signos externos o demarcadores de su auto-identificación" (Adams, 1994: 191). Entre los elementos más efectivos para mantener unidas a las etnias están el uso de un lenguaje común, control sobre algún territorio, algún nivel de endogamia, y rituales seleccionados (Adams, 1994). 
Llevando esta perspectiva al análisis político, las etnias actuales no son grupos inmutables y cerrados originados en los albores de la humanidad. Muy por el contrario: se trataría de particulares dinámicas sociales que surgen en los tiempos modernos como resultado de "tipos específicos de interacciones entre las dirigencias políticas de estados centralizadores y las elites de grupos étnicos subordinados, especialmente, aunque no exclusivamente, en las periferias de estos estados" (Brass, 1991: 8-9). Según este punto de vista, la etnicidad como fenómeno político no es una constante inalterable, sino más bien el resultado de fluctuantes configuraciones políticas y sociales. Estas configuraciones son elaboradas y construidas por las elites locales o regionales, las que se apoyan en, distorsionan, o a veces incluso fabrican materiales simbólicos tomando elementos étnicos de las culturas de los grupos que quieren representar con el fin de preservar su bienestar o su existencia, o para obtener ventajas políticas y económicas para sus grupos y también para sí mismos (Brass, 1991: 8). Así, la etnicidad es vista como un potencial instrumento de las elites de los grupos étnicos, las que operan como intermediarios culturales para instrumentalizar las dimensiones básicas de las identidades étnicas.

Esta perspectiva sobre la etnicidad como fenómeno social es llamada "contextualista/situacional", "instrumentalista", o "estructuralista", y considera la etnicidad como producto de interacciones sociales que dependen del contexto social e histórico, y que son "instrumentables" (i.e., manipulables) por los intereses colectivos de los grupos sociales. La etnicidad como fabricación social reflejaría las diferencias objetivas en la posición o ubicación de grupos específicos en la estructura social, lo cual es fluctuante en términos históricos (Hechter, 1986: 13). Esto quiere decir que la condición étnica de un grupo es básicamente el resultado o expresión históricamente determinada de algún tipo de organización social desde cuyo interior los individuos se ubican a sí mismos y se relacionan con otros. En otras palabras, los contextualistas sostienen que la interacción de la sociedad con el grupo es lo que define la etnicidad del individuo, tanto la de cada miembro del grupo como la del extraño o no miembro, y el individuo no tiene desde siempre cristalizada en sí la identidad étnica que su sociedad le atribuye. Según todo esto, no podría hablarse de un individuo étnico, sólo de grupos étnicos (Stavenhagen, 1990: 9).

En tanto la etnicidad no sería un atributo permanente o invariable de un sector social específico, sino que estaría en función de factores históricos, socioculturales y económicos, la intensidad de la etnicidad puede variar también según el momento histórico y la propia situación del grupo. En gran medida, y según esta posición analítica, la etnicidad es el resultado momentáneo de una auto-identidad construida o "negociada" por el grupo en función a su auto-percepción como una comunidad, y en respuesta también a cómo el resto de la sociedad percibe al grupo. El contextualismo, pues, busca explicaciones básicamente de tipo histórico, sociocultural y económico; es decir, de tipo contextual, situacional o estructural: contextos, situaciones y estructuras en el conjunto social que expliquen la percepción y actuación de ciertas colectividades como grupos étnicos.

La explicación es instrumentalista en tanto ve la etnicidad como algo manipulable y como epifenómeno (Hechter, 1986: 13), como un fenómeno secundario que acompaña otros fenómenos o dinámicas sociales de tipo estructural y que es causado o se deriva 
de ellas. Así, "una etnia puede activar su etnicidad cuando lo considere políticamente conveniente o necesario, así como disminuir o ignorar su etnicidad cuando ésta no se considere útil" (Stavenhagen, 1990: 10). En efecto, los sentimientos étnicos (y por ende, los propios grupos étnicos) no sólo pueden desaparecer en algunos momentos históricos para luego volver a manifestarse en otros momentos, sino que incluso pueden surgir comunidades étnicas nuevas en base al "re-descubrimiento" por algunos grupos de su propia etnicidad. Puede también darse el caso, por último, de que algunos individuos busquen reconocerse como parte de algún grupo étnico o asumir cierta identidad étnica, o adjudicarse las características o cualidades culturales que el resto de la sociedad atribuye a ciertos segmentos o estratos de la población.

La perspectiva contextualista ha adquirido bastante aceptación en décadas recientes porque los "primordialistas" han debido reconocer, especialmente en relación con el actual surgimiento de movimientos étnico-nacionalistas, que la intrínseca y supuestamente inmutable "naturaleza humana" no es una explicación suficiente para la variación en la intensidad que el sentimiento étnico experimenta en diferentes momentos históricos. Todo esto lleva a la percepción de los grupos étnicos como actores colectivos calculadores, interesados en promover sus propios valores para maximizar la obtención de beneficios materiales a través del vehículo de la identidad comunal, pero manipulando el principio grupal excluyente para provecho único de los miembros del grupo (Young, 1993: 22). Desde esta perspectiva, en fin, el análisis social debería identificar los factores políticos que pueden activar la identidad étnica, descubrir los activistas culturales que articulan estos movimientos ideológicamente, y analizar a las élites que explotan dichas solidaridades.

Los contextualistas tienen, sin embargo, limitaciones en cuanto a sus esfuerzos por explicar por qué las pasiones movidas por la etnicidad y el nacionalismo son tan fuertes y extendidas, al punto de parecer trascender las meras circunstancias contextuales para alimentarse de emociones o sentimientos profundamente arraigados (Kellas, 1991: 8), a la vez que pueden llevar a colectividades enteras a desatar niveles de agresión, violencia y ensañamiento difícilmente comprensibles exclusivamente en términos de intereses materiales (Young, 1993: 23).

Al intentar complementar las fortalezas de las posturas primordialista y contextualista, se puede considerar que, pudiendo ser la etnicidad una fabricación social, enmarcada en jerarquías sociales que buscan justificar la existencia de diferencias y legitimarlas, muchos de los miembros o participantes de estos grupos pueden sentir ciertos símbolos o ideologías como si fueran basados en la parte más "esencial” de su identidad y asumirlos y movilizar su propia etnicidad en ciertos momentos como si perteneciera a la larga tradición interna del grupo, a uno de sus rasgos propios más profundos y permanentes. Por otra parte, en muchos de los países del Tercer Mundo, el conflicto étnico sería el resultado de las desigualdades sociales y políticas que el colonialismo estableció dentro de las sociedades multi-étnicas, en las cuales las jerarquías sociales coinciden en buena medida con las diferencias étnicas (Stavenhagen, 1990: 10). En general, habría que analizar las relaciones entre Estado y etnicidad para lograr una mejor comprensión de la naturaleza, causas, y dinámicas de los conflictos étnicos alrededor del mundo. 
Por ejemplo, y para referirnos a nuestro país, un campesino de la sierra puede ser visto como "indio" por los habitantes urbanos, mientras que frente a otros habitantes rurales puede ser considerado "mestizo" si es que habla castellano y está frente a otros campesinos quechua-hablantes monolingües. Más aún, la propia persona puede concientemente manipular estas diferentes posiciones, de modo que su etnicidad se define en relación con otras personas y dentro del contexto concreto y específico de la interacción social. De acuerdo a esta concepción, la etnicidad del individuo no es, pues, algo dado o marcado exclusivamente de antemano (adscrito o heredado), ni tampoco siempre definido por su pertenencia a ciertas colectividades mayores. La persona hace un uso selectivo de su repertorio sociocultural, de sus experiencias vivenciales, de su pericia en la interacción social, de los símbolos externos, de referentes no sólo tomados de su posición en la estructura de producción sino también en la del consumo, en particular de los objetos y prácticas culturales, para tomar la postura más ventajosa posible que el contexto interaccional —en juego con su "capital sociocultural" y su nivel de autoconciencia o reflexividad social - le permite. Como dice Quirin (1993: 200), "las gentes tienen la capacidad de crear sus propias identidades, pero deben hacerlo dentro de contextos político-económicos y socioculturales diversos y cambiantes".

\section{ETNICIDAD Y CENSOS}

En los países donde se han ejecutado los Censos, mayormente la definición del contenido temático en la cédula censal es producto de una serie de factores como: demanda de información de sectores sociales, prioridades de información según criterios de política estatal, comparabilidad nacional e internacional, calidad y oportunidad, fuentes alternativas de información, extensión del cuestionario, así como la heterogeneidad, regionalización y diferencias existentes en el desarrollo socioeconómico y cultural del país y la factibilidad de registro censal, entre otros. Para ello se recurre a una serie de mecanismos como talleres o reuniones temáticas de trabajo con instituciones públicas, privadas y académicas. Es en este contexto que se debe ubicar la inclusión del ítem sobre etnicidad en un censo nacional de población.

Después de haber considerado rápidamente algunos planteamientos recientes en torno a los conceptos sobre raza y etnicidad, revisaremos los indicadores más utilizados en los censos de la región para medir la variable de pertenencia étnica. Sin embargo, se debe tener en cuenta que las reflexiones teóricas sobre etnicidad aquí vistas plantean algunos disyuntivas para el ejercicio censal de tipo convencional. Por un lado, ¿cómo capturar, mediante un "corte situacional" aplicado de modo universal al conjunto de la población, toda la dinámica cultural y situacional que se desenvuelve en continuo cambio según el contexto en que se encuentre cada grupo étnico? (10) Por el otro, teniendo en cuenta la economía de tiempo y espacio para el levantamiento de información

(10) Los representantes de países asistentes al II Todos Contamos (e.p.), mayoritariamente reconocieron que existe una profunda heterogeneidad entre los grupos étnicos de la región como para establecer una norma que permita identificarlos o clasificarlos fácilmente. Por otra parte, procesos diversos de mestizaje o también llamado "proceso de aculturación" hacen cada vez más difícil su delimitación conceptual. 
que impone el propio procedimiento censal, ¿cómo enunciar una pregunta (o a lo más, dos preguntas) lo más eficientemente formulada en términos de obtener la mayor información con el menor número de palabras, y que sea aplicable a todas y cada una de las personas que habitan en un país plurilingüe y multicultural? En síntesis, ¿cuánta información sobre etnicidad se puede obtener a través de un censo nacional de población que por acuerdo internacional se debe (y por razones de economía, sólo se puede) aplicar una vez cada diez años? ¿Qué valor tiene y qué tanto sirve cualquier información sobre etnicidad obtenida de este modo?

Una primera respuesta general y sencilla sobre esto es que se debe reconocer el carácter básicamente "cuantitativo" de la información obtenida a través de un censo. Es el consabido trueque de extensión por calidad, o entre cantidades y cualidades de lo registrado. Ante esto, cabe plantear que un censo nacional de población sólo puede ofrecer, para temas como el de la etnicidad, elementos para construir un marco muestral de estudios que tienden a estar geográfica o socialmente focalizados, los cuales a su vez requieren de cuestionarios más exhaustivos y especializados para poder captar un tipo particular de información. Por otra parte, en algunos países de la región se ha optado en algunas ocasiones por preparar instrumentos adicionales al cuestionario de aplicación universal; por ejemplo, para comunidades campesinas y/o localidades donde residen mayoritariamente los integrantes de poblaciones originarias. Estas consideraciones básicas deben orientar la decisión sobre el criterio más adecuado para la realidad de cada país.

\section{1. "Raza"}

En el primer encuentro regional de Institutos de Estadística y Censos, Todos Contamos 2000, el criterio de identificación fenotípica fue desestimado por varios ponentes. Se dijo al respecto que la opción para identificar a los individuos por observación del encuestador, basada en aspectos como la vestimenta y los rasgos físicos del entrevistado "no es recomendada, pues conlleva un alto grado de subjetividad, por lo que no ha sido ampliamente utilizada" (Mejía \& Moncada, 2000: 51). Por otra parte, se mencionó que el uso de rasgos fenotípicos como indicadores de pertenencia étnica es un criterio que "desconoce el proceso de mestizaje existente y para efectos censales quedaría a juicio del empadronador, lo que no es conveniente" (Bodnar, 2000: 81). De allí la importancia de que los pueblos indígenas y grupos afrodescendientes participen activamente en la determinación de las variables básicas que permitan captar sus particularidades sociodemográficas. Su presencia no se debe limitar a esta etapa, puesto que los insumos que proporcionen estos grupos son claves para la definición de estrategias de utilización y difusión de la información, y deben estar disponibles para que esta información les sirva para su enriquecimiento cultural y para su interacción con la sociedad envolvente (Encuentro Internacional Todos Contamos: Los Censos y la Inclusión Social, en prensa). 
En ciertos casos, el criterio de identificación fenotípica puede ser de alguna utilidad para la captación de las poblaciones afrodescendientes, pero es mayor el riesgo de que una clasificación fenotípica contribuya a fortalecer categorías culturales de raza o a legitimar socialmente la distinción de las personas por su apariencia, todo lo cual puede fomentar actitudes discriminatorias en el ordenamiento sociocultural. Además, está comprobado que el uso de este criterio muchas veces provoca rechazo tanto en los informantes como en los propios empadronadores. Aparte de esto, en algunos países la aplicación de este criterio hasta podría entrar en conflicto con sus constituciones políticas en tanto éstas proclaman que nadie debe ser diferenciado por apariencia o color. Sería entonces bastante problemático para una institución oficial, como lo son los Institutos de Estadísticas y Censos, incluir un criterio de registro censal basado exclusivamente en los rasgos anatómicos externos de la población (12).

\section{2. Idioma}

Es un criterio frecuentemente utilizado por los países de la región. Es común considerar al lenguaje con el cual las personas se comunican usualmente como el medio de transmisión de la cultura y de todos sus componentes, tal como hemos indicado más arriba. Sin embargo, desde un punto de vista metodológico este indicador por sí solo es insuficiente para identificar a todos los grupos étnicos de la región. En particular, no serviría para identificar a los afrodescendientes, en tanto tienen mayoritariamente como lengua materna el castellano. En cuanto a los pueblos originarios, también tiene limitaciones ante los procesos de cambio cultural por el que algunos de ellos transitan, especialmente en las generaciones jóvenes y las poblaciones indígenas urbanas, donde por lo general se presenta una notoria pérdida de las lenguas originarias. Por otra parte, el uso de este criterio llevaría a incluir a personas quienes eventualmente hayan aprendido a hablar idiomas indígenas.

Ante esta situación, se ha optado entre registrar el idioma que frecuentemente se habla en el hogar o adscribir la pertenencia étnica según el idioma en que se aprendió a hablar (lengua materna). Cualquiera de estas alternativas por sí sola constituye una solución todavía parcial si es que se escoge solamente una de estas opciones para convertirla en la única pregunta para identificar la etnicidad en un censo nacional aplicado universalmente a toda la población. En efecto, mediante este único indicador sólo estaríamos atribuyendo un origen étnico a los respondientes, pero no necesariamente nos dará información sobre su situación actual o sobre la vigencia de la pertenencia étnica, especialmente si ha habido desplazamiento geográfico o debilitamiento de vínculos comunales. Por lo demás, este criterio presenta similares limitaciones que el anterior con respecto a los grupos afrodescendientes.

(12) Cabe indicar, sin embargo, que este criterio resulta de gran utilidad en encuestas y estudios a profundidad cuando se busca identificar situaciones de discriminación racial, siempre y cuando se maneje con sumo cuidado teórico, metodológico y procedimental. 


\section{3. Ubicación geográfica}

Es un criterio usado por algunos países de la región y siempre secundado por otras preguntas. Es útil en algunos países donde las comunidades indígenas y afrodescendientes se encuentran concentradas en territorios específicos, que no es la situación de la mayoría dado que existe un fuerte proceso migratorio del campo a la ciudad. En nuestro país en las últimas décadas se ha observado un fuerte proceso migratorio de población indígena, especialmente de la sierra, hacía las ciudades en busca de mejores perspectivas de condiciones de vida. Por otra parte, no todos los grupos afrodescendientes del Perú se concentran en comunidades con territorios específicos. Este criterio sería útil mayormente para el caso de los pueblos originarios de la Amazonía, por lo cual no podría ser escogido como el único ni principal para la situación de todos los grupos étnicos. En todo caso, podría optarse por aplicar una cédula aparte, especialmente si se trata de actualizar registros de comunidades campesinas y de pueblos amazónicos, los cuales tienen regímenes de derecho especiales de tenencia de tierra y de pertenencia a las organizaciones comunales.

\section{4. Autoidentificación o autorreconocimiento de pertenencia}

Este criterio recoge la pertenencia étnica por declaración espontánea del individuo y que se aproxima más al concepto actual de etnia. Uno de los problemas que presenta este criterio para los censos nacionales proviene de la potencial subdeclaración, producto del mestizaje o prejuicios negativos especialmente en situaciones percibidas como adversas. Sin embargo, la sobredeclaración también es un riesgo cuando se usa este criterio para la identificación y focalización de grupos étnicos fuera del procedimiento censal nacional, como resultado de simpatía por la cultura o la causa indígena en un momento dado o debido a la percepción de posibles beneficios que podrían obtenerse por la aplicación de las políticas sociales destinadas a favorecer a estos grupos de población.

A pesar de los inconvenientes que presenta esta última opción, su aplicación parece ser la más consecuente con las concepciones de etnicidad aquí esbozadas. En todo caso, retomemos una de las preguntas de fondo: ¿a quiénes queremos contar? ¿A quiénes queremos identificar? Esto depende, lógicamente, de nuestra concepción de grupo étnico. Así, si aceptamos que el autorreconocimiento es un componente definitorio de la etnicidad, entonces la pregunta principal sobre pertenencia étnica en el censo tendría que ser esa. Pero no se trata solamente de ser consecuentes con la teoría social. También debemos ser prácticos en cuanto a la necesidad de comprometer a los grupos étnicos en su propio empoderamiento y en el fortalecimiento de su agencia social, de modo que se involucren activa y participativamente en los proyectos de desarrollo que más les convenga emprender, involucramiento que ayuda a garantizar la viabilidad y sostenibilidad de todas estas iniciativas. Sin autorreconocimiento no hay identificación, y sin identificación no hay compromiso. 


\section{Referencias Citadas}

II Encuentro Internacional Todos Contamos: Los Censos y la Inclusión Social (en prensa)

ADAMS, R. N., 1994 - Strategies of Ethnic Survival in Central America. In: Nation-States and Indians in Latin America (Urban, G. \& J. Sherzer eds): 181-206; Austin: U. of Texas P.

AMERICAN ANTHROPOLOGICAL ASSOCIATION, 2002a - American Anthropological Association Response to OMB Directive 15: Race and Ethnic Standards for Federal Statistics and Administrative Reporting. Descargado de Internet (http://www.aaanet.org/ gvt/ombdraft.htm ) el 29/10/2002.

AMERICAN ANTHROPOLOGICAL ASSOCIATION, 2002b - American Anthropological Association Statement on "Race". Descargado de Internet (http://www.aaanet.org/stmts/ racepp.htm) el 29/10/2002.

ANDERSON, B. 1983 - Imagined Communities: Reflexions on the Origin and Nationalism. Londres: Verso.

BATES, R., 1999 - Etnicity, Capital Formation, and Conflict. Washington, D.C.: World Bank.

BILLINGTON, R., SHEELAGH STRAWBRIDGE, L. \& FITZSIMONS, A., 1991 - Culture and Society: A Sociology of Culture. London: Macmillan.

BODNAR, Y., 2002 - Los grupos étnicos en los censos: el caso colombiano. Memorias del Primer Encuentro Internacional Todos Contamos: 69-100; Bogotá: Departamento Administrativo Nacional de Estadística.

BRASS, P. A., 1991 - Ethnicity and Nationalism: Theory and Comparison. New Delhi: Sage.

BRETON, R. J.L., 1983 - Las etnias. Barcelona: Oikos-tau, .

CHIRIF, A. (comp.), s.f. (1978?) - Introducción. In: Etnicidad y ecología: 9-14; Lima: Centro de Investigación y Promoción Amazónica (CIPA), primera edición.

DEGREGORI, C.I., 1993 - Identidad étnica, movimientos sociales y participación política en el Perú. In: Democracia, etnicidad y violencia política en los países andinos. 113-133; Lima: IFEA /IEP.

DERUYTTERE, A., 1997 - Indigenous Peoples and Sustainable Development: The Role of the Inter-American Development Bank. Washington, D.C.: InterAmerican Development Bank.

FLÓREZ, C. E., MEDINA, C. \& URREA, F., 2001 - Understanding the cost of social exclusion due to race or ethnic background in Latin America and Caribbean countries. Washington, D.C.: Inter American Development Bank.

FRIEDMAN, E., 1993 - Ethnic Identity and the De-Nationalization and Democratization of Leninist States. In: The Rising Tide of Cultural Pluralism.222-242; Madison(Wisconsin): The U. of Wisconsin P.

GEERTZ, C., 1973 - The Interpretation of Cultures. Nueva York: Basic Books.

HECHTER, M., 1986 - Theories of Ethnic Relations. In: The Primordial Challenge: Ethnicity in the Contemporary World Stack, (John F., Jr. ed.): 13-24; Nueva York: Greenwood.

JACKSON, J. E., 1994 - Being and Becoming an Indian in the Vaupés. In: Nation-States and Indians in Latin America (Urban, G. \& J. Sherzer (eds.): 131-155; Austin: U. of Texas P., 1994 (2 $2^{a}$ edición).

KELLAS, J. G., 1991 - The Politics of Nationalism And Ethnicity. Basingstoke (Inglaterra): Macmillan Education.

MARTIN, J. N. \& NAKAYAMA, T. K., 1997 - Intercultural Communication in Contexts. Mountain View (Ca): Mayfield.

MEJÍA, J. A. \& MONCADA, G., 2002 - Las variables de etnia y raza en las encuestas de hogares en América Latina y el Caribe. In: Memorias del Primer Encuentro Internacional Todos Contamos: 48-58; Bogotá: Departamento Administrativo Nacional de Estadística. 
Memorias del Primer Encuentro Internacional Todos Contamos. 2002 - Bogotá: Departamento Administrativo Nacional de Estadística.

MERRIAM-WEBSTER, 1987 - Webster's Ninth New Collegiate Dictionary. Springfield (Massachusetts): Merriam-Webster.

NAGI, S. Z., 1992 - Ethnic Identification and Nationalist Movements. Human Organization, $\mathbf{N}^{\mathbf{0}}$ 51 (4): 307-317.

PERÚ 1944 - Censo Nacional de Población y Ocupación 1940. Lima: Ministerio de Hacienda y Comercio, Dirección Nacional de Estadística.

PLANT, R., 1998 - Issues in Indigenous Poverty and Development. Washington, D.C.: Inter American Development Bank.

QUIRIN, J., 1993 - Ethnicity, Caste, Class, and State in Ethiopian History: The Case of the Beta Israel (Falasha). In: The Rising Tide of Cultural Pluralism (Young, C., ed.): 200-221; Madison (Wisconsin): The U. of Wisconsin P.

REAL ACADEMIA ESPAÑOLA, 1984 - Diccionario de la lengua española. Madrid: EspasaCalpe.

REAL ACADEMIA ESPAÑOLA, Diccionario de la Lengua Española, XXII edición. Consulta descargada de internet (www.rae.es) el 13/01/2003.

RENSHAW, J., M. MAILLEUX S., \& VON BREMEN, V., 2001 - Guidelines for Socio-cultural Analysis. Washington, D.C.: Inter American Development Bank.

RIBEIRO, D., 1979 - Etnicidad: Indígenas y Campesinos. Perú: Identidad Nacional. Lima: Centro de Estudios para el Desarrollo y la Participación.

RIGGINS, S. H., 1992 - The Media Imperative: Ethnic Minority Survival in the Age of Mass Communication. In: Ethnic Minority Media: An International Perspective. 1-20; Newbury Park (Calif.): Sage.

SMITH, R. C., s.f. (1978?) - El Proyecto Amuesha/Yanachaga. In: Etnicidad y ecología. (Chirif, A. compilador). 157-176; Lima: Centro de Investigación y Promoción Amazónica (CIPA).

STACK, J. F., Jr., 1986 - Ethnic Mobilization in World Politics: The Primordial Perspective. In: The Primordial Challenge: Ethnicity in the Contemporary World (Stack, J.F., Jr. ed.): 111; Nueva York: Greenwood.

STAVENHAGEN, R., 1990 - The Ethnic Question. Conflicts, Development, and Human Rights. Tokio: United Nations U.P.

STOLCKE, V., 1992 - Sexo es a género lo que raza es a etnicidad. Márgenes, N 9: 65-90.

URBAN, G, \& SHERZER, J. (eds.), 1994 - Introduction: Indians, Nation-States, and Culture. In: Nation-States and Indians in Latin America: 1-18; Austin: U. of Texas P., (2a edición).

VAN DEN BERGHE, P., 1978 - Race and Ethnicity: A Sociobiological Perspective. In: Ethnic And Racial Studies; $\mathbf{N}^{\mathbf{0}} \mathbf{1}$ : 401-411.

VILLARREAL, M., ECHEVERríA, A., PEZ, D., VALENCIA, J. \& AYESTARÁN, S. Identidad étnica y movilización política.

WADE, P., 1997 - Race and Ethnicity in Latin America. Chicago: Pluto.

WILLIAMS, B. F., 1989 - A Class Act: Anthropology and the Race to Nation Across Ethnic Terrain. Annual Review of Anthropology, $\mathbf{N}^{\mathbf{0}}$ 18: 401-444.

WILLIAMS, R., 1983 - Keywords: A Vocabulary of Culture and Society. Nueva York: Oxford U.P.

YOUNG, C. (ed.), 1993 - The Dialectics of Cultural Pluralism: Concept and Reality". In: The Rising Tide of Cultural Pluralism: 3-35; Madison (WI): The U. of Wisconsin P. 